\title{
El Trabajo Social como forma de control: un análisis desde la perspectiva de la Epistemología histórica
}

\author{
José María Morán Carrillo; Manuel Flores Sánchez²
}

Recibido: 28/11/2016 / Revisado: 16/12/2016/Aceptado: 15/06/2017

Resumen. El Trabajo Social en su devenir histórico se alía con el poder y profesionaliza la asistencia ante las presiones y desajustes del capitalismo. El control es sustantivo para comprender el Trabajo Social, de forma que su expertise opera utilizando el discurso y las prácticas institucionales; es decir, a través de una concepción epistemológica que sanciona determinados saberes, prácticas y formas de ayuda. El presente trabajo defiende que el Trabajo Social logra su efecto cuando genera subjetividades en la gente y transmite certidumbre a través del ejercicio del poder. En secuencia histórica, se demuestra cómo, una vez alcanzada la emancipación del modelo estamental, la sociedad liberal y el individualismo sientan las bases del capitalismo; este es el espacio natural donde el Trabajo Social ejercerá una forma de control como mediador entre el capital y el trabajo. Su presencia institucional, su mimetismo con la Iglesia católica y la vinculación ideológica de las primeras escuelas y procesos formativos hacen necesario acudir al concepto de control para explicar el surgimiento del Trabajo Social en España.

Palabras clave: Control social; Trabajo Social; Iglesia católica; formación; nacionalcatolicismo

\section{[en] Social Work as a means of control: an analysis from the perspective of historical Epistemology}

\begin{abstract}
Historically, social work has allied with power and professionalised care in response to the pressures and imbalances of capitalism. Control is key to understanding social work, in the sense that its expertise is implemented using institutional discourse and practices; that is, via an epistemological conception that endorses certain forms of knowledge, practices and support. This work argues that social work is effective when generating subjectivities among people and transmitting certainty through the exercise of power. In chronological order, it is shown how following the achievement of emancipation from the stratified model, liberal society and individualism formed the bases for capitalism. This is the natural space in which social work will exercise a form of control as mediator between capital and labour. Its institutional presence, its mimicry of the Catholic Church and the ideological connection of the first schools and training processes make it necessary to resort to the concept of control to explain the rise of social work in Spain.
\end{abstract}

Key words: social control; social work; Catholic Church; training; National Catholicism

Sumario: Introducción. 1. La prehistoria: el control de la mendicidad. 2. Protohistoria: socialismo y apostolado, dos formas de "ganarse" al pueblo. 3. Nacimiento: institucionalización del control, nacionalcatolicismo y primeras escuelas. 3.1. La Escuela de Trabajo Social de Barcelona. 3.2. Las Escuelas de Trabajo Social de Madrid. 3.3. Las Escuelas de Trabajo Social de la Sección Femenina. 3.4. Las Escuelas de Trabajo Social de Cáritas. 4. Conclusiones. 5. Referencias bibliográficas.

Cómo citar: Morán Carrillo, J. M.; Flores Sánchez, M. (2018) El Trabajo Social como forma de control: un análisis desde la perspectiva de la Epistemología histórica, en Cuad. trab. soc. 31(2), 321-331.

\footnotetext{
Universidad Pablo de Olavide, España jmmorcar@upo.es

2 Universidad Pablo de Olavide, España

mflosan@upo.es
} 


\section{Introducción}

Partiendo de un enfoque de Epistemología histórica que pone el énfasis en los procesos de formación y disolución de ideas, valores, categorías y objetos científicos y particulares (Mardones, 1991; Rivera, 2008; Becerra, 2016), a continuación se expone la relación entre los conceptos de trabajo social y control. El control, presente en la sociología de la disciplina como atavismo asociado al poder, lo define Janowitz (1995) como una respuesta a la forma más efectiva de que un grupo social pueda regularse a sí mismo de acuerdo a un conjunto de principios morales y legítimos que impliquen una reducción del control coercitivo. Oliver (2005), por otro lado, considera que el control es un sistema configurador del orden social que actúa como promoción de la socialización del ciudadano y sancionador de las desviaciones a través de instituciones (escuela, familia, comunidad, policía, tribunales, etc.) que constituyen subsistemas de control social.

Desde los orígenes reformistas hasta el reconocimiento de los derechos subjetivos del ciudadano, la acción social ha negado tradicionalmente la caridad limosnera para estimular una beneficencia que provea control y fuerza de trabajo útil para el liberalismo moralizante. A continuación, partiendo de la secuencia -prehistoria, protohistoria y nacimiento- se afirma que la labor asistencial ha sido un proceso más vinculado al imaginario moralizante, liberal y utilitarista que al idealismo humanista de atención al desvalido. La ética funcionalista, por lo tanto, sienta las bases del marco filosófico del Trabajo Social que establece una relación causal entre incompetencia, exceso, pobreza y control.

\section{La prehistoria: el control sobre la mendicidad}

La "prehistoria" del Trabajo Social remite a aquellas experiencias que, sin constituir un cuerpo teórico o profesional stricto sensu, suponen una primera iniciativa de control o protoforma de política social, ejercida sobre los me- nesterosos, pobres y enfermos. La llegada de la dinastía de los Borbón en 1700 y la influencia de la Contrarreforma en Europa, marcan el inicio de un Estado interesado en racionalizar, reordenar y centralizar la toma de decisiones en los ámbitos políticos y sociales. La Administración Pública ilustrada trata de distanciarse del renacimiento inmovilista, adoptando medidas transformadoras en los más diversos campos: reorganización de la Administración Local, colonización de tierras, saneamiento de la Hacienda Pública, mejora de las comunicaciones, modernización del ejército y expansión de la cultura a través de la divulgación de las artes, las ciencias y las letras.

Con el mismo espíritu reformador, pero en el campo de la asistencia social, se desarrolla una iniciativa de control denominada "policía de pobres" encaminada a ejercer vigilancia de las familias ${ }^{3}$. El simbolismo que establecía una correlación funcional entre pobre, limosna y salvación cambia en el siglo XVIII, y las competencias en materia de pobres pasan a ser una forma de control para los ilustrados. A partir de este momento, el Estado instaura una vigilancia férrea de la vida social y económica de la población, estableciendo una correspondencia entre miseria (individual y familiar) y pobreza pública. La institución religiosa acostumbrada a ejercer el monopolio benéfico como algo propio, percibe la reforma ilustrada como cuestionamiento de su primacía sobre el negocio de la miseria y los espacios simbólicos de salvación. Sarasa (1993), aludiendo a tal actitud reactiva de la Iglesia, afirma:

El enfrentamiento de la Iglesia española con las ideas originadas en la ilustración la llevó a posturas cerradas y extremadamente conservadoras $[\ldots]$ ni las sucesivas desamortizaciones de bienes eclesiásticos, ni la Ley de Beneficencia de 1822, por la que se crearon las juntas de beneficencia provinciales y nacionales y que, en teoría, conferían mayor poder a las autoridades públicas, significaron un desplazamiento importante de la Iglesia del campo asistencial (p. 136).

En la lucha por ocupar el espacio de control y gestión de recursos dedicados a los pobres,

Jacques Doncelot refiere en su libro La policía de las familias (1998), cómo a lo largo de los siglos XVIII y XIX el poder ilustrado desarrolla estrategias de control para luchar contra la mendicidad y la pobreza en un intento de reconvertir la miseria en capital social aprovechable. Cuando el poder se convierte en un problema de producción, se hace necesario administrar las poblaciones $\mathrm{y}$, consecuentemente, intervenir sobre las familias. 
la Iglesia pone en juego su extraordinaria capacidad de adaptación espoleada por la inercia de la contrarreforma; este mimetismo será una constante ante los embates de gobiernos progresistas y constituciones liberales por limitar su influencia. Aunque de forma general el siglo XVIII cambia el modelo de gestión de la miseria, las políticas correctoras se concentran en reprimir el limosneo por fomentar la ociosidad y vicios que inducían a los pobres a vivir sin trabajar. A partir de este momento, el mendicante pierde su función mediadora de salvación y aureola mística para ser considerado una carga para el Estado y un riesgo para la sociedad.

A mediados del siglo XVIII, la exhibición del infortunio empezará a ser perseguida y solo a aquellos que por razones justas no puedan trabajar les ayudará el Estado; no en vano en 1749 se prohíbe el ejercicio del pordioseo como forma de orientar a los miserables hacia el trabajo productivo (Garcés, 1996). El resultado de la reforma iluminada determinará que, a un siglo vista de la propuesta de Luis Vives, el Estado fiscal se encargue de controlar el juego, el consumo excesivo de alcohol y a todos aquellos que sin ser pobres reales o desempleados se dediquen a vivir sin trabajar.

En el marco del "Despotismo ilustrado", Carlos III (1716-1788) engrandece el Estado a la par que acomete una importante reforma social; él es el primero que interpreta la pobreza como fenómeno que ralentiza el desarrollo y pone en riesgo la paz social al promover desordenes populares y movilizaciones reivindicativas. Según Alemán (1991), las acciones institucionales y legislativas de mayor envergadura que se llevaron a cabo por Carlos III abarcan tres frentes: el "correctivo", mediante la fundación del Hospicio de San Fernando; las de "previsión", a través de la introducción de los montepíos; y las "asistenciales" con el establecimiento de las diputaciones de barrio.

En el campo de las medidas correctivas, el Hospicio nace como una institución orientada a aquellos que no pudiesen ganarse el sustento ${ }^{4}$; su filosofía supone el retorno a las casas de Misericordia a modo de profilaxis que priva de libertad y somete a severa disciplina. La institución no se limitaba a dar cobijo y sustento, sino que pretendía disuadir a los menesterosos y pedigüeños, so pena de internamiento en Hospicio y reinserción mediante trabajo en régimen de asistencia, prisión o castigo (Trinidad, 1988).

De las tres iniciativas ilustradas, la más interesante es la Diputación de Barrio como forma primigenia de control y política social reglamentada. Las diputaciones se crearon por el Decreto en 1778, y se constituyeron en una institución dedicada a la asistencia a domicilio, en oposición a la política represiva de los Hospicios. Sarasa (1993) afirma que los alcaldes de barrio responsables de su funcionamiento, "significaron un paso adelante en la gestación de los futuros trabajadores sociales a cargo de la Administración pública" (p. 136). Su misión era la siguiente:

Topografiar detenidamente la zona de su jurisdicción; establecer una relación del número de vecinos, domicilio y actividad a la que se dedican $[\ldots]$ con el fin de atender y socorrer a los pobres, enfermos y desocupados, en su propio domicilio" [...] se encargan de recoger a los pobres y de llevarlos a los hospicios y de transportar los niños abandonados a la Inclusa (Trinidad, 1988, p. 103).

Con perspectiva histórica, el siglo XVIII es el momento en el que racionalismo y teocentrismo colisionan para generar una nueva pragmática que acepta el racionalismo instrumental como armazón filosófica del liberalismo. A su vez, la emancipación liberal de los corsés económicos e ideológicos de la sociedad estamental habilita una pequeña burguesía que con el paso del tiempo devendrá en capitalismo. Con un reformismo que aboga por una sociedad orgánicamente estructurada, el modelo asistencial combinará medidas de gestión, represión, control y atención de la pobreza que, convenientemente filtradas por un funcionalismo utilitarista trata de desarrollar las capacidades y habilidades del menesteroso para (re)integrarlo al sistema productivo.

\footnotetext{
Entre los años 1750 y 1800, se construyó una red importante de hospicios que muestran la cara más represiva y controladora de los ilustrados. Uno de los más importantes fue la Casa de Corrección de San Fernando en Madrid puesto en marcha por el ilustrado Pablo de Olavide. El hospicio, al que la terminología oficial llamaba "Depósito" o "Corrección” es el exponente del régimen carcelario aplicado a los internos en el sentido más estricto de la palabra (Trinidad, 1988).
} 


\section{Protohistoria: socialismo y apostolado, dos formas de controlar al pueblo}

La ciencia social del XVIII y principios del XIX se caracteriza por el auge del utilitarismo, el positivismo y el laicismo como sustrato necesario para entender el reformismo social y los movimientos reivindicativos que culminan en la Internacional socialista. En el caso del reformismo español del siglo XIX, son fundamentales para entender el Trabajo Social dos acontecimientos: la creación de la Comisión de Reformas Sociales $(1883)^{5}$ y la encíclica Rerum Novarun (1891). Ambos sucesos son piezas básicas para aproximarse a las primeras iniciativas de Trabajo Social como forma de control y atención a los necesitados.

La Comisión de Reformas Sociales (CRS) se creó en 1883 como instrumento de mediación entre el movimiento obrero y el reformismo burgués. La crisis económica y unas reformas económicas realizadas de espaldas a la realidad requieren un instrumento del Estado que gestione el conflicto entre la burguesía adinerada (que ve disminuir su tasa de beneficio), y la masa trabajadora (que sufre insalubridad en talleres mugrientos y pésimas condiciones de vida).

Según De la Calle Velasco (1984), este será el contexto en el que aparece por primera vez la expresión "Trabajo Social" en el preámbulo de la Ley que crea la Comisión de Reformas Sociales de mano de su mentor, Segismundo Moret $^{6}$. Interpretando a Moret, lo que se propone es que, antes de acometer cualquier reforma, esta se analice en sus causas mediante una forma de "trabajo social" que incorpore la opinión de aquellos a los que la reforma afecta (Molina Sánchez, 1994). Al margen de la semántica del concepto, la política reformista iniciada por la Comisión incorpora dos avances para la política social y el consenso interclasista; es decir, el uso de la mediación del trabajador social entre el Estado y los necesitados y la toma en consideración de la opinión de los mediadores para cualquier iniciativa sugerida por la Comisión.

Por otra parte, la encíclica De Rerum Novarum (1891) supone un giro radical de la tradición católica frente a la cuestión social, siendo este cambio relevante para explicar el surgimiento de la asistencia social como comprobaremos más adelante. Sin lugar a dudas, la nueva sensibilidad viene estimulada por la agitación social e ideológica de la Internacional Socialista y el potencial riesgo de alejamiento de la doctrina que ello implica para las bases.

La respuesta del Vaticano a los retos de la cuestión social expresada a través de De Rerum Novarum será el catolicismo social ${ }^{7}$ (Gutiérrez Resa, 1993; Molina Sánchez, 1994). Pero, en el caso español, ¿qué hace que el catolicismo social se convierta en un instrumento de control político? La respuesta es clara: la Iglesia católica, al ser consciente de que las ideas libertarias y colectivistas son "competencia" en el mantenimiento de la feligresía y para combatir la desafección de la doctrina, promueve el asociacionismo confesional con la intención de mantener su influencia en la vida social española.

La estrategia desarrollada por la Iglesia se concibe como una "tercera vía" entre el liberalismo burgués y el colectivismo obrero con actitud corporativa, pero adaptada en este caso a los nuevos tiempos (Sarasa, 1993). En la misma dirección, Miranda (2004) entiende que el nuevo talante responde a una actitud estratégica manifestada en la renuncia al Estado confesional, pero no al control del Estado a través de la conquista de las clases trabajadoras. En la lid por no ceder al empuje de partidos políticos y sindicatos, la institución promoverá sindicatos confesionales, escuelas nocturnas y centros sociales que compensan la influencia de los ateneos libertarios (anarquistas) y casas

\footnotetext{
En paralelo a la creación de la Comisión de Reformas Sociales en España (1883), en Alemania el Canciller Bismark promueve igualmente en 1883 una extensa legislación en materia de protección social. Las iniciativas legislativas son el resultado de la expansión de la Internacional socialista que, emprendida por Federico Engels y Carlos Marx, inicia su internacionalización en 1848 con la publicación del Manifiesto Comunista en Londres.

6 La CRS se creó por Real Decreto de 5 de diciembre de 1883 a instancias del ministro de Gobernación, Segismundo Moret y Prendergast. El texto se publica en la «Gaceta», el 10 de diciembre de 1883 con el ampuloso título de: Comisión para el estudio de las cuestiones que interesan a la mejora o bienestar de las clases obreras, tanto agrícolas como industriales, y que afectan a las relaciones entre capital y trabajo.

Rerum Novarum expresa con claridad la disyuntiva a la que está sometida la clase obrera: "En este estado de cosas, los obreros cristianos se ven ante la alternativa o de inscribirse en asociaciones de las que cabe temer peligros para la religión o constituir entre sí sus propias sociedades, aunando de este modo sus energías, para liberarse valientemente de esa injusta e insoportable opresión. ¿Qué duda cabe de que cuantos no quieran exponer a un peligro cierto el supremo bien del hombre habrán de optar sin vacilaciones por esta segunda postura?" (Punto 17).
} 
del pueblo (socialistas). De forma particular, el empeño del catolicismo español por no ceder su espacio social se desarrollará en base a una triple estrategia: los congresos católicos, los círculos obreros y la creación de organizaciones católicas de defensa social (Tusell, 1975).

Uno de los instrumentos y origen del catolicismo social son los congresos católicos que surgen en 1881 como Unión Católica ${ }^{8}$. Los congresos se ubican en la Restauración (última década del siglo) y están orientados a promover una legislación social en búsqueda de armonía entre el capital y el trabajo frente a la lucha de clases. En la misma línea de los congresos, pero en este caso por medio de un "sindicalismo católico", se crearon los círculos obreros y patronatos obreros que "como instrumento privilegiado de acción social católica es el preferido y recomendado constantemente en los Congresos" (Montero, 1988, p. 169). E1 promotor de los círculos obreros fue el Padre Vicent (1903), quien con mentalidad paternalista y conservadora supo llevar el mundo del trabajo a la acción pública de los católicos. La labor de los círculos iba más allá de la acción benéfico-social y educativa, e incorporaban a su actividad sindical instituciones escolares (escuelas dominicales, nocturnas, de barrio) que, orientadas a la moralización y catequización, perseguían controlar los avances de sindicatos obreros entre las masas trabajadoras (Montero, 1988). Bajo un sucinto análisis, todo apunta a que el interés social de la Iglesia nace, al menos aparentemente, con más vocación instrumental que pastoral, más estratégica que vocacional y más terrenal que trascendente.

\section{Nacimiento: institucionalización del control, nacionalcatolicismo y primeras escuelas}

En el caso del Trabajo Social, la atmósfera que ve prosperar la disciplina es el corolario de cambios socioeconómicos creados por la Revolución Industrial y la necesidad de encauzar los problemas asistenciales en las masas obreras. En Europa la atención social se hizo urgente, una vez finalizada la I Guerra Mundial (1914-1917), ya que el volumen de damnificados por el conflicto estimuló la apertura de escuelas y técnicas apropiadas de ayuda. La primera organización internacional privada de Servicio Social fue la Unión Católica Internacional de Servicio Social (UCISS), con sede en Bruselas (1925), y cuyos programas docentes han influido de manera notable en la Escuelas de Trabajo Social ${ }^{9}$. En el caso español, y con semejanzas notables al resto de Europa, la amplitud con la que liberalismo e industrialismo manifiestan la pobreza urbana y rural hace que la asistencia deje de ser una actividad meramente paliativa para pasar a ocupar espacios progresivamente orientados al desempeño profesional y consolidación corporativa. La realidad impone, por consiguiente, una respuesta funcional al problema del pauperismo industrial que canalizado estratégicamente por la Iglesia católica se concreta en la creación de escuelas a lo largo del país bajo el marco ideológico del catolicismo social.

Siguiendo a Molina Sánchez, a comienzos del siglo XX el ambiente económico y social en España propician la fusión de fuerzas sociales públicas y privadas (Iglesia católica, cooperativas, empresas, círculos obreros) en un frente conservador sensible a la política de reforma y paz social. Las iniciativas sociales y humanistas se convertirán en plataforma de análisis, denuncia y propuestas a las diversas necesidades obreras existentes en el momento. Origen del movimiento social fue el Padre Gabriel Palau, creador en Barcelona en 1908 de Acción Social Popular. La iniciativa de Palau es importante para el origen del Trabajo Social en España ya que utiliza las "semanas sociales" como plataforma reivindicativa del obrerismo confesional.

Aunque las dificultades para una acción progresista fueron amplias, la República incorpora en su Constitución (1931) derechos de gran potencialidad políticosocial (Constitución de Weimar) y la constitucionalización de la cuestión social. La Constitución republicana rompió la inercia de las cartas precedentes e

El Obispo de Barcelona, impactado por la primera celebración del $1^{\circ}$ de Mayo en 1890, propone un proyecto de seguro social obligatorio para la clase trabajadora con financiación estatal y patronal. Dicha propuesta es remitida al Congreso Católico de Zaragoza de 1891 para ser debatida con el título "Capital-Trabajo". (Montero, 1988)..

9 La UCISS contribuyó en gran medida a la expansión de centros de formación en Trabajo Social por América del Sur, Asia y Oceanía. En el año 1947, una vez finalizada la Segunda Guerra Mundial, la UCISS obtuvo el Estatuto Consultivo en el Consejo Económico y Social, en la Organización de Estados Americanos y en el Consejo de Europa, así como en UNESCO, OIT, UNICEF Y FAO (De la Red,1993). 
incorporó la responsabilidad del Estado en los problemas sociales. El programa social de la República se sustanció en el artículo 46, que garantizaba las condiciones necesarias para una existencia digna con extensión a garantías sobre vejez, enfermedad o paro forzoso, entre otros. Otras legislaciones creadas para el control de los outsiders (Ley de vagos y maleantes de 25 de abril de 1933$)^{10}$, se orientaron a la represión de la mendicidad, poniendo en práctica los carnés de pobre y las fichas policiales (De la Red y Brezmes, 2003).

En el juego político del primer tercio del siglo XX la Iglesia, si bien forzada por el excesivo anticlericalismo de los movimientos obreros y sindicales, comparte de manera generalizada una afinidad ideológica con los poderes fácticos (terratenientes, nobleza, militares no afines, Guardia Civil) que ven en la Segunda República un contubernio judeo-masónico y bolchevique que arremete contra España y el catolicismo (Preston, 2011). Este es el contexto de nacimiento de las primeras experiencias de asistencia social en España y, muy particularmente, de la primera Escuela de Barcelona. Destinadas a cumplir con los objetivos del catolicismo social y del nacionalcatolicismo, las Escuelas abiertas se crean para adoctrinar a la clase obrera y formar a trabajadoras sociales competentes para el ejercicio de la acción caritativa y apostólica (Estruch y Güell, 1976; Molina Sánchez, 1994). Las Escuelas de formación más importantes abiertas en España entre 1932 y 1972 fueron las siguientes.

\subsection{La Escuela de Trabajo Social de Barcelona}

La primera experiencia de formación reglada aunque no oficial de asistencia social en Espa- ña se inicia en Barcelona en 1932 imitando los modelos preexistentes en Europa. La escuela se abre por iniciativa del doctor Raúl Roviralta $^{11}$ y Antonia Ferreras, bajo la denominación de "Escuela de Asistencia Social para la Mujer". La Escuela se asocia, algunos meses más tarde, a la Unión Católica Internacional de Servicio Social (UCISS), y propone fines culturales y educativos en la línea de la Escuela Católica de Servicio Social de Bélgica, fundada en 1920. De acuerdo a la situación política en 1932, los contenidos docentes prescindieron de toda oficialidad confesional de acuerdo a las circunstancias políticas del momento, aunque una vez concluida la contienda estos se modifican para hacerlos acordes al nacionalcatolicismo ${ }^{12}$ impuesto por la alianza Iglesia-Estado (Molina Sánchez, 1994).

Finiquitada la guerra civil, la Escuela de Asistencia Social para la Mujer vuelve a abrir sus puertas en 1939, dependiendo ahora de la Acción Católica Femenina que modifica su nombre por el de "Escuela para el Hogar y Obras Sociales Femeninas" (Estruch y Güell, 1976). En estos momentos la oferta académica incluye materias como religión, encíclicas y moral. Hacia 1941 el centro vuelve a cambiar de denominación por la de "Escuela Católica de Enseñanza Social", afiliándose en 1944 al Secretariado Diocesano de Beneficencia.

Decana del Trabajo Social español, la "Escuela de Visitadoras Sociales Psiquiátricas" vuelve a cambiar de nombre en enero de 1953, bajo el auspicio del psiquiatra Ramón Sarró y en colaboración con la Sección Femenina. El doctor Sarró se había formado en Estados Unidos y a su regreso a la cátedra de Psiquiatría pone mucho interés en transmitir el modelo psicosocial a las alumnas matriculadas. En su interés por reproducir la práctica desarrollada

10 El proyecto de Ley de Vagos y Maleantes fue presentado en el Gobierno de Azaña manteniendo el concepto de vagancia como delito; posteriores reformas consintieron limitarlo a meros "estados peligrosos" susceptibles de ser sometidos a medidas de seguridad. Según la ley eran considerados peligrosos los vagos habituales, rufianes y proxenetas, aquellos que viven del esfuerzo ajeno, los mendigos profesionales, los que viven de la mendicidad ajena, putas, menores, enfermos mentales o lisiados, ebrios, toxicómanos, traficantes de drogas y armas, todos aquellos que tengan trato asiduo con delincuentes y gentes de mal vivir, etc. Ley de Vagos y Maleantes, Capítulo I, artículo 2. Gaceta de Madrid, número 217 del 5 de agosto de 1933.

11 El Doctor Roviralta es responsable de imprimir en 1937 el texto Los problemas de Asistencia Social en la Nueva España. Esta publicación puede considerarse como la primera sobre Trabajo Social en nuestro país y se inspira, según su autor, en la utilizada por la Escuela Superior Fascista de Asistentes Sociales de Roma (De la Red, 1933).

12 Pérez Díaz (1994) define el nacionalcatolicismo en la España de los años 1940 y 1950 bajo las siguientes características: a) el monopolio religioso de la Iglesia; b) esta situación es reconocida y avalada por el Estado que considera la Iglesia católica como religión oficial; c) la confesionalidad del Estado convierte a la Iglesia en institución rectora de la vida social y cultural del país; d) la Iglesia se ve beneficiada de importantes apoyos económicos, subvenciones, exenciones e inversiones que contribuyen a hacer más fuerte su posición respecto a iniciativas surgidas desde el ámbito civil; e) la Iglesia, durante más de dos décadas, se introdujo en círculos muy próximos al poder dada la "militancia" de algunos de sus miembros en alguna de sus agrupaciones (Opus Dei); f) como consecuencia de sus prerrogativas, la Iglesia católica tuvo la habilidad para ocupar cultural y moralmente, especialmente en las clases medias, espacios privados culturales y de conciencia (pp. 150-175). 
por las/los social workers anglosajonas, Sarró introduce esta práctica en las tareas de soporte, control y seguimiento de casos que los psiquiatras les requerían. Su iniciativa es importante para la profesión al formar varias generaciones de profesionales en un momento en el que Trabajo Social se encontraba teórica y metodológicamente desierto. La Escuela de Visitadoras Sociales Psiquiátricas incorpora, en el curso 1963-1964 a estudiantes masculinos y amplía los contenidos psicosociales a nuevos espacios sanitarios; ese mismo curso modifica también su nombre por el de "Escuela de Visitadoras Sociales-Psicólogas" (Molina Sánchez, 1994).

\subsection{Las Escuelas de Trabajo Social de Madrid}

Entre los años 1939 y 1957 se abren en Madrid dos centros dedicados a la formación asistencial: la Escuela de Formación Familiar y Social y la Escuela Superior de Asistentes Sociales San Vicente de Paúl ambas, según Llovet y Usieto (1990), de reconocida militancia católica. La Escuela de Formación Familiar y Social se inauguró en octubre de 1939 y sus promotoras fueron Rosario Rodríguez y María Sabater, bajo la titularidad de las Hijas del Corazón de María. La ascendencia católica de sus fundadoras, así como las exigencias políticas del momento, justifican que la redacción de estatutos, elaboración de plan de enseñanza y elección de profesores sean aprobados por el cardenal primado Tomás y Gomá ${ }^{13}$. Siguiendo a Molina Sánchez (1994, el cuadro de profesorado estaba compuesto por "eminentes catedráticos de la universidad de Madrid y prestigiosas autoridades civiles y eclesiásticas"; y su cometido central era "la preparación de Asistentes Sociales y la creación de obras de asistencia y educación popular" (pp. 87-90). La Escuela pasó en 1943 a formar parte de la Unión Católica Internacional de Servicio Social (UCISS).

El 10 de mayo de 1957, las Hijas de la Caridad inauguran un centro en Madrid denominado Escuela Superior de Asistentes Sociales "San Vicente de Paúl. La Escuela formaba específicamente a las hermanas de la congregación en el intento de mejorar y tecnificar la labor asistencial y apostólica que venían desarrollando.
Egresadas tres promociones de profesionales religiosas, se considera conveniente incorporar a laicos al centro con la motivación de "que las personas seglares se formaran en centros de toda solvencia moral" (p.96). Las escuelas madrileñas aportan consistencia a una profesión incipiente de forma que, cuando se presentó al Ministerio de Educación la solicitud de reconocimiento oficial en el año 1964, "la Escuela había formado ocho promociones de religiosas, en un total de 171 alumnas y cinco promociones de seglares, que comprendían 201 alumnas" [...] "en ese mismo año 1964, nueve Escuelas de Asistentes Sociales estaban dirigidas por religiosas que habían sido formadas en esta Escuela de Madrid" (Molina Sánchez, 1994, p.96).

\subsection{Las Escuelas de Trabajo Social de la Sección Femenina}

En el marco de la "Nueva España" (Ley 28 de diciembre de 1939) se encomendó a la Sección Femenina de Falange Española Tradicionalista y de las Juntas Ofensivas Nacional-Sindicaslistas (JONS) la formación políticosocial de la mujer española, sin consideración de clases sociales y en cualquiera de los ámbitos de su vida: trabajo, cultura, educación, política, deporte, según Molina Sánchez. Su misión se orientó a los cuidados sanitarios y la higiene, atendiendo además a: programas generales de socorro, suministro de alimentos y cuidado de huérfanos. Durante la contienda, la imagen de la Sección Femenina no estuvo exenta de ser utilizada como instrumento de control y propaganda, ya que la idea de las mujeres falangistas que entraban en las provincias recién "liberadas" entrañaba un enorme capital político y el régimen no perdió la oportunidad de elaborar una retórica en la que desinfección y limpieza de la nación daba la oportunidad de alejar el espíritu de los españoles de las doctrinas malsanas (Richmond, 2004).

En marcha el segundo gobierno franquista (agosto de 1939), la Sección Femenina institucionalizó una política de género y subordinación al hombre imitando las experiencias alemana Frauenschaft e italiana Fasci Femminili donde educación e ideología eran dos caras de la misma moneda. En este punto, la

3 El cardenal Gomá apoyó los objetivos de la Iglesia tradicional y nacionalcatólicista finalizada la Guerra Civil. Gomá, en una de sus homilías, dice lo siguiente: "Gobernantes haced catolicismo a velas desplegadas si queréis hacer la patria grande; ni una ley, ni una cátedra, ni una institución, ni un periódico fuera o contra Dios y su Iglesia en España”. González Seara, III Congreso Nacional de T.S. (1976). 
organización dirigida por Pilar Primo de Rivera comenzó a especializarse en la atención, gestión y coordinación de obras sociales y benéficas heredadas de la guerra; todo ello con la intención de atender a la población menos favorecida y siguiendo parámetros de control católicos y paternalistas.

La Sección Femenina fue tras la Iglesia católica el segundo organismo promotor de Escuelas de Trabajo Social en España. En los diez años que transcurren entre 1953 y 1963, la organización de Pilar Primo de Rivera abre cinco Escuelas en Barcelona (1953), Madrid (1957), Córdoba (1962), Granada (1962) y Salamanca (1963). Las escuelas, unidas a otros programas de corte "social" representaron para las mujeres un poderoso vector ideológico con base en un ideario de justicia social que incluía ciertas dosis de militarismo y algo de populismo antimonárquico y antiburgués.

En materia de asistencia social lo que se inició como actividades voluntarias y altruistas, se transformó con el paso del tiempo en una necesidad de tecnificación y profesionalización para sus afiliadas ${ }^{14}$. Este fue el motivo que despertó el interés de Falange por la apertura de Escuelas de Formación, ya que como pensaba su Delegada Nacional, "esta nueva Profesión encajaba perfectamente dentro de la labor que venía realizando la Sección Femenina” (Molina Sánchez, 1994, p.77).

Con el paso de los años, el declive de la Sección Femenina refleja el ocaso de valores asociados a la doctrina política de los años treinta. En la medida en la que el primer ciclo desarrollista permite a España liberarse de las prácticas autárquicas, nuevas ideas socavan el equilibrio entre pureza doctrinaria y pragmatismo modernizante. Aunque las necesidades asistenciales y educativas van en aumento como consecuencia del desarrollismo, el ritmo de cambio que experimentaba el país deja al margen el ideario mantenido por la Revolución Falangista. La mujer española, necesitada de conquistar espacios fuera del hogar, colisiona con la legislación machista del Fuero de los Españoles, ensanchando la brecha entre retórica y realidad (Richmond, 2004). La falta de interés por las motivaciones "joseantonianas" así como la lejanía del conflicto para las mujeres, lleva a un lento declive de afiliación a partir de los años sesenta que le restará presencia y fuerza institucional hasta su desaparición.

\subsection{Las Escuelas de Trabajo Social de Cári- tas}

El interés de los católicos españoles por amortiguar el impacto del problema obrero se materializa en el esfuerzo de Cáritas por formar técnicos sociales en escuelas bajo su titularidad. Siguiendo a Salinas Ramos (1977), la creación de las Escuelas de Asistencia Social surge de la necesidad de la Sección Social de Cáritas (1957) por superar el control benéfico y sustituir el socorro material por una acción tecnificada, planificada y de capacitación. La creación de Escuelas de Cáritas tiene su inicio en 1958, año en el que se fundaron quince escuelas a lo largo del territorio nacional. Dada la inflación de centros en tan escaso lapso de tiempo, sus promotores se vieron obligados a generar en 1959, como órgano coordinador, la Federación Española de Escuelas de la Iglesia de Servicios Social (FEEISS). La Federación tenía entre otros cometidos orientar la formación, reciclar a los docentes y organizar cursillos y seminarios a nivel nacional e internacional.

Un segundo aspecto a considerar en la labor de Cáritas son los informes FOESSA (Fomento de Estudios Sociales y Sociología Aplicada) como diagnóstico y análisis de la situación social en España. En la necesidad de hacer llegar al gran público los contenidos de los informes, Cáritas crea en 1964 la editorial Euroamérica dependiente de su Federación. Partiendo de FOESSA, la Federación confecciona las primeras publicaciones a través de la "Hoja Informativa" en folios ciclostilados y con secciones dedicadas a legislación, noticias y bibliografía ${ }^{15}$. De lo expuesto se deduce que la labor de Cáritas es esencial para entender el

14 Conscientes del incremento de los problemas sociales que imponía un incipiente desarrollismo y la inaplazable especialización para trabajar con criterio, el formato elegido por los dirigentes falangistas fue la creación de un "Curso Libre de Asistencia Social", orientado a convertir en Asistentes Sociales a mandos y afiliados de acuerdo a "convocatoria reservada" que Pilar Primo de Rivera dirige a sus Delegadas provinciales en 1961. Los estudios se encontraban en colisión académica con la oferta formativa de la Iglesia católica que para el año 1964 dirigía, de acuerdo a las directrices de la UCISS, veintisiete escuelas frente a las cinco de la Sección Femenina. Molina Sánchez (Molina Sánchez, 1994, pp. 74-75).

15 En un primer momento, y ante la falta de personal competente que pudiese formar a los pioneros bajo paradigmas menos autoritarios, se aprovecharon ayudas de Naciones Unidas para establecer contactos con expertos extranjeros que impartiesen seminarios 
nacimiento del Trabajo Social en España. Tal afirmación se sustenta en tres argumentos; su contribución al conocimiento de la realidad social española a través de los sucesivos informes FOESSA, la creación de las Escuelas para asistentes sociales abiertas desde $1958 \mathrm{y}$, en último lugar, el importante número de técnicos sociales formados que a mediados de los noventa llega a cerca de los diez mil (Molina Sánchez, 1994).

En definitiva y con los datos suministrados se puede arribar a las siguientes conclusiones: las Escuelas de Trabajo Social nacen en su totalidad al amparo de la Iglesia católica y la Sección Femenina en un momento histórico condicionado por la confesionalidad e ideología de sus dirigentes hasta el punto de determinar el sesgo profesional. La visión secuenciada de las aperturas entre los años 1932 y 1983, permite afirmar que la aparición de las Escuelas se realiza en dos etapas bien definidas: una primera de veinticinco años o "etapa de letargo" (1932-1957) condicionada por la Guerra Civil y postguerra (se abren cinco escuelas), y una segunda de "expansión" (1958-1968) que permite la apertura de treinta y siete centros (total de 42) de los que veintidós son tuteladas por la Sección Social de Cáritas.

Si aplicamos el andamiaje conceptual bourdiesiano (Bourdieu, 2000) al despertar del Trabajo Social en España, la expansión de las Escuelas debe entenderse como una clara estrategia de capitalización social, académica y simbólica. Según nuestra forma de entender, los años 1950 y 1960 suponen el momento en el que la libido sciendi se incorpora a la disciplina como resultado de la simbiosis entre acción social y pretensión científica. Es precisamente en este momento cuando se ponen las bases de las estrategias de reproducción, conservación y funcionamiento del conjunto de instituciones que académicamente representarán al Trabajo Social en España.

\section{Conclusiones}

Si entendemos la acción social y los Servicios Sociales como instituciones de control social burocráticamente articulados, cabe recordar que de los tres tipos de dominación legítima propuesto por Weber (legal, tradicional y carismática), la legal o burocrática es la forma de dominación técnicamente más pura (Weber 1993). Bajo este prisma y en términos históricos, es evidente que la acción social se ha organizado bajo el control de la Iglesia y el Estado como formas de poder y magistratura institucional. Bajo tales formas y como consecuencia, la legitimidad para ejercer la acción social caritativa y/o profesionalizante se ha asentado históricamente en un conjunto de actividades metódicas, coactivas y de legitimidad orientada a ejercer control sobre gobernados, protegidos o educados.

Aunque los profesionales de la asistencia social no fueron observadores pasivos a lo largo de la historia, desde el siglo XVI hasta nuestros días la gestión de la pobreza discurre en paralelo a la modernidad y la expansión liberal. En términos de control-poder, se puede afirmar que los procesos de institucionalización (política, educativa, económica) avanzan en la medida que progresa la autoridad del Estado. En lo referido a la acción asistencial, Estado e Iglesia se convierten en campos que reivindican el uso de formas legítimas de violencia física y simbólica sobre familias, menesterosos, tullidos y empobrecidos (Donzelot, 1998). La autoridad del Estado, en adelante, será reforzada por la posesión de un conjunto de capitales con poder de coacción bajo formas de capital jurídico, cultural e identitario.

Desde la perspectiva del capital simbólico que supone la profesionalización de la asistencia, la disciplina erradica progresivamente su relatividad funcional al fundamentar los espacios institucionales (Iglesia y Estado) y certificados oficiales (formación) como forma de control. Como dice Weber [1922], el Estado es quien posee el monopolio de la violencia simbólica legítima o, utilizando palabras de Bourdieu, es depositario del sentido común y de la razón que garantiza la posesión de la formación y certificados escolares (Bourdieu, 2000). A partir de este análisis la disciplina queda habilitada para conservar, transformar, explicar y clasificar el mundo o, lo que es lo mismo, adquiere capacidades performativas para revelar o modificar las cosas que ya existen.

En definitiva, el espacio social que representa el Trabajo Social tiende a funcionar

y circuitos formativos; entre ellos podemos citar los cursos ofrecidos en Madrid por Nadir Gouvea Kfouri (1959); en San Sebastián por Elda Florentino (1961); en Barcelona por Giambruno y Pagani (1961) y en la zona centro, levante y sur por Helen Casidy (1962) (Molina Sánchez, 1994, pp. 65-66). 
como capital simbólico al definir estilos de vida y status a través de la desigual posesión de capitales. Tales capitales confieren a los agentes (de forma no deliberada, natural) legitimación sobre sus acciones, ideas o intereses.
Ayer, hoy y mañana la pobreza, la dignidad o la clase, retraducen esquemas de percepción y control que expresan sin quererlo el estado de las relaciones de poder sobre la que actúan las/ os profesionales asistenciales en España.

\section{Referencias bibliográficas}

Alemán, Carmen (1991). El sistema público de servicios sociales en España. Granada: Impredisur.

Álvarez-Uría, Fernando (1988). Los visitadores del pobre. Cuatro siglos de acción social, de la beneficencia al bienestar social. Madrid: Siglo XXI.

Álvarez Junco, José (1988). La comisión de reformas sociales: intentos y realizaciones. 4 siglos de acción social, de la beneficencia al bienestar social. Madrid: Siglo XXI.

Becerra Batán, Marcela (2016). La cuestión de la Epistemología Histórica como estilo epistemológico. Epistemología e Historia de la Ciencia (vol. 1). Córdoba: Centro de Investigaciones de la Facultad de Filosofía y Humanidades. Universidad Nacional de Córdoba. Argentina.

Beltrán, M. (1988). Ciencia y Sociología. Madrid: CIS - Siglo XXI.

Bourdieu, P (2000). Poder Derecho y Clases Sociales. Bilbao: Desclée.

De la Calle Velasco, María Dolores (1984). La Comisión de Reformas Sociales: de la represión al análisis de la conflictividad social. Studia histórica. Historia contemporánea 2. Salamanca: Universidad de Salamanca.

De la Red, Natividad. (1993). Aproximaciones al Trabajo Social. Madrid: Consejo General de Colegios de Diplomados en Trabajo Social y Asistentes Sociales.

De la Red, Natividad y Brezmes, Mercedes. (2003). Trabajo Social en España. En: T. Fernández García y C. Alemán Bracho (coords.), Introducción al trabajo social (pp.131-152). Madrid: Alianza Editorial.

Donzelot, Jacques (1998). La policía de las familias. Valencia: Pre-textos.

Estruch, J. y Güell A.M. (1976). Sociología de una profesión. Los asistentes sociales. Barcelona: Ediciones Península.

Garcés, Jorge (1996). Ideas y administración de servicios sociales a través de la historia. Sistema político y administrativo de los Servicios Sociales. Valencia: Tirant lo Blanch.

González Seara, Luis (1976). Pautas y Directrices Teóricas de la Acción Social. Memoria III Congreso Nacional de Asistentes Sociales. Sevilla: FEDAAS.

Gutiérrez Resa, A. (1993). Cáritas española en la sociedad del bienestar 1942-1990. Barcelona: Hacer.

Hernández Aristu, Jesús (2004). Trabajo Social en la Postmodernidad. Zaragoza: Certeza.

Janowitz, M. (1975). Teoría Social y Control Social. Revista de Ciencias Sociales, 6. Buenos Aires: Facultad de Ciencias Sociales. Universidad de Buenos Aires.

Ley de Vagos y Maleantes (1933). Disponible en: http://galeon.com/franquismo/web/LVaMa.pdf (21 noviembre 2016)

Llovet, Juan José y Usieto Ricardo (1990). Los trabajadores sociales, De las crisis de identidad a la profesionalización. Madrid: Editorial Popular.

Mardones, José María (1991). Filosofia de las ciencias humanas y sociales. Materiales para una fundamentación cientifica. Barcelona: Anthropos.

Miranda, Miguel (2004). De la caridad a la ciencia. Pragmatismo, Interaccionismo $\quad$ simbólico y Trabajo Social. Zaragoza: Mira Editores.

Molina Sánchez, María Victoria (1994). Las enseñanzas del trabajo social 1932-1983. Estudio socio-educativo. Madrid: Universidad Pontificia de Comillas.

Montero, Feliciano (1988). Catolicismo y reforma social en España en el tránsito del siglo XIX al XX: cuatro siglos de acción social, de la beneficencia al bienestar social. Madrid: Siglo XXI.

Oliver, P. (2005). El concepto de control social en la historia social: estructuración del orden y respuestas al desorden. História Social, 51. Madrid: Arce.

Pérez Díaz, Víctor (1994). La primacía de la sociedad civil. Madrid: Alianza.

Preston, Paul (2011). El holocausto español. Barcelona: Debate.

Renes (1977). Explicar para actuar: los estudios e investigaciones en Cáritas. Trabajando por la justicia. Cincuenta años de solidaridad. Aniversario 50 años de Cáritas. Madrid: Cáritas española. 
De Rerum Novarum (1891). Encíclica, León XIII. Recuperado de: http://www.vatican.va/holy_father/leo_ xiii/encyclicals/documents/hf_l-xiii

enc_15051891_rerum-novarum_sp.html (16 de noviembre de 2016).

Richmond, Katleen (2004). Las mujeres en el fascismo español. La sección femenina de la Falange, 1934 - 1959. Madrid: Alianza.

Rivera Palomino, Juan (2008). Epistemología histórica y las ciencias sociales. Investigaciones Sociales 12(21). Lima: Facultad de Ciencias Sociales, Universidad Nacional Mayor de San Marcos.

Salinas Ramos, Francisco (1977). La acción social de Cáritas (1947-1997). Trabajando por la justicia. Cincuenta años de solidaridad. Aniversario 50 años de Cáritas. Madrid: Cáritas española.

Sarasa, Sebastián (1993). El trabajo social en España: Avatares de una profesión. El servicio de lo social. Madrid: Ministerio de Asuntos Sociales.

Trinidad, Pedro (1988). Asistencia y previsión social en el siglo XVIII: cuatro siglos de acción social. De la beneficencia al bienestar social. Madrid: Siglo XXI.

Tusell, Javier (1975). La época regeneracionista: La revolución desde arriba (1899-1913). La España del Siglo XX. Desde Alfonso XIII hasta la muerte de Carrero Blanco. Barcelona: Dopesa.

Weber, Max (1993, [1922] Economía y Sociedad. Madrid: Fondo de Cultura Económica. 